\title{
An energy approach for impact wear in water environment
}

Thibaut Souilliart ${ }^{\mathrm{a}, \mathrm{b}}$, Emmanuel Rigaud ${ }^{\mathrm{a}}$, Alain Le Bot ${ }^{\mathrm{a}}$, Christian Phalippou ${ }^{\mathrm{b}}$

a Laboratoire de Tribologie et Dynamique des Systèmes, UMR CNRS 5513, Ecole Centrale de Lyon, Université de Lyon, 36 avenue Guy de Collongue, 69134, Ecully, France

${ }^{b}$ Commissariat à l'Energie Atomique et aux Energies Alternatives CEA-Saclay, DEN, DANS, DM2S, SEMT, DYN, F-91191 Gif-sur-Yvette, France

\begin{abstract}
Wear induced by repetitive impacts between steam generator tubes and anti-vibration bars in pressurized water reactors is studied with an analytical impact wear apparatus. Repetitive impacts between an Inconel tube sample and a stainless steel flat bar target are performed in water environment at ambient temperature. Incident energy and angle of impacts are controlled, normal and tangential loads during impact are measured as well as rebound energy and angle of impacts. Impacts characteristics are deeply analyzed and interdependences are highlighted. In particular, the evolution of restitution coefficient, ratio between tangential and normal impulses during impacts, energy loss and sliding distance during impacts versus incidence angle are identified. Impact wear is found to be strongly dependent to impact dynamics, in particular it is observed to be proportional to energy loss during impacts and dependent to incidence angle with a maximum near $20^{\circ}$ to the tangential axis. Microscope observation of the wear scars shows the existence of numerous abrasive scratches whose length corresponds to the sliding distance during impact. An impact model is introduced to express energy loss and sliding distance as functions of incidence angle, incident energy, restitution coefficient and impulse ratio. Experimental wear is observed to be dependent on both incidence angle and energy loss.
\end{abstract}

\section{Highlights}

Impact wear of steam generator tubes against anti-vibration bar is studied in water environment. Restitution coefficient, impulse ratio, energy loss and sliding distance during impacts are analyzed. Micro-abrasive processes are highlighted through the analysis of the wear scars topography. Wear in water environment is observed to be dependent on both incidence angle and energy loss.

\section{Keywords}

Impact wear

Sliding distance

Friction coefficient

Energy of impact

Inconel 690 wear

Lubricated friction 
Nomenclature

\begin{tabular}{|c|c|}
\hline$d_{n}$ & Normal contact duration: $d_{n}=t_{r n}-t_{i n}$ \\
\hline$d_{t}$ & Tangential contact duration: $d_{t}=t_{r t}-t_{i t}$ \\
\hline$e$ & Restitution coefficient of impact \\
\hline$f$ & Excitation frequency \\
\hline$f_{\text {Engel }}$ & Slip factor \\
\hline$l_{s}$ & Sliding distance during impact \\
\hline$m$ & Projectile mass \\
\hline$m_{a}$ & Apparent mass seen by one contact asperity: $m_{a}=m / N_{a}$ \\
\hline$t$ & Time \\
\hline$t_{i n} ; t_{i t}$ & Time location of normal/tangential load beginning during impact \\
\hline$t_{r n} ; t_{r t}$ & Time location of normal/tangential load end during impact \\
\hline$v_{r} ; v_{r n} ; v_{r t}$ & Rebound velocity; Normal/Tangential component of rebound velocity \\
\hline$v_{i} ; v_{i n} ; v_{i t}$ & Incident velocity; Normal/Tangential component of incident velocity \\
\hline$D_{t}$ & Tangential position of the projectile \\
\hline$E^{*}$ & Equivalent Young modulus in Hertz theory \\
\hline$F_{n} ; F_{t}$ & Normal/Tangential component of load \\
\hline$F_{n m} ; F_{t m}$ & Maximum value of normal/tangential contact load during impact \\
\hline$K$ & Impact wear energy coefficient \\
\hline$N_{a}$ & Number of contact asperities \\
\hline$P_{n} ; P_{t}$ & Normal/Tangential impulse during impact \\
\hline$R_{q}$ & Roughness parameter \\
\hline$T_{i}$ & Incident kinetic energy of the projectile \\
\hline$T_{L} ; T_{L n} ; T_{L t}$ & Energy loss; Normal/Tangential component of energy loss \\
\hline$T_{L}^{*}$ & Normalized energy loss \\
\hline$V^{-} ; V^{+}$ & Negative/Positive wear volume \\
\hline$V_{i m p}^{-}$ & Wear volume per impact \\
\hline$\alpha_{i}$ & Incidence angle of the projectile \\
\hline$\alpha_{r}$ & Rebound angle of the projectile \\
\hline$\beta$ & Asperity radius of curvature \\
\hline$\mu$ & Impulse ratio \\
\hline$\mu_{c}$ & Critical impulse ratio \\
\hline$\mu_{\text {end }}$ & Impulse ratio at the end of wear test \\
\hline$\mu_{k}$ & Kinetic friction coefficient \\
\hline
\end{tabular}

\section{Introduction}

In Pressurized Water Reactors (PWR), Steam Generator (SG) tubes are subjected to repetitive impacts against Anti-Vibration Bars (AVB) which sometimes induce significant wear. When becoming too large, wear can lead to plug the SG tube. Therefore, the understanding of the wear formation processes and the analysis of the relationship between impacts characteristics and SG tube wear is a major concern for the safety of PWR. 
Several types of impact wear exist according to the motions and the involved bodies [1]. Whether impacts involve substantial incident mass and low velocity (percussive impacts) or low mass and large velocity (particle erosion), two categories of wear models are proposed. Concerning percussive impact wear, Engel [2-4] proposes a model taking account of the surfaces conformance during wear formation and based on a strong dependence on the shear stress. Levy [5], Connors [6], Frick [7] and Hoffman [8] propose wear models based on a proportionality with load and sliding distance derived from Archard's equation. Lewis [9] takes over the Engel model by adding a new dependency with sliding distance. Gessesse [10] and Attia [11] extend the delamination theory of sliding wear from Suh to percussive impact wear, with a specific interest to the contact geometry at the asperity scale. Concerning erosion wear, three types of models can be distinguished [12]. Finnie [13,14] and Bitter [15] propose models for a rigid grain cutting into a ductile metal. Hutchings [16], Follansbee [17], Ratner [18] and Sundararajan [19] develop fatigue models which involve a critical accumulated strain required to generate wear. Jahanmir extends the delamination theory of sliding wear from Suh [20] to erosion wear.

Impact characteristics are deeply studied by Stronge [21]. The analysis of velocities, kinetic energy, forces, friction, stick and slip regions of the contact during impact results in a rich but complex formulation of impact characteristics. Brach [22,23] uses a classical impulse and momentum theory to express these characteristics, especially the energy loss during an impact. It leads to simpler and more intelligible formulations with a high degree of physical meaning. Brach observes a good correlation between the energy loss during an impact and erosive wear results from literature. No comparison is carried out between this model and percussive impact wear observations.

A lot of experimental studies have been carried out in the last decades about impact wear in nuclear field. Guinot [24] and Zaghdoudi [25] have listed many impact test machines and gather them into two categories whether or not priority is given to reproducing real PWR environment. Ko [26] , Cha [27] and Blevins [28] among others studied impacts and wear with real environment test machines. Sorokin [29], Rice [30] and Pick [31] developed analytical test machines to study normal impact only. These test machines are expected to have better characteristics than the ones which reproduce real environment but the precision of the dynamics control is very different from one apparatus to another. A lack of analytical experimental apparatus with a large range of possible incidence angles is to be noted.

In the present work, wear of a SG tube sample subjected to repetitive impacts against an AVB sample is studied in water environment. Section 2 presents the experimental apparatus that has been designed and used. Section 3 presents a detailed statistical analysis of the impacts and their characteristics. Section 4 presents an analysis of the wear scars and volumes based on topographic measurements and energy considerations.

\section{Experimental details}

\subsection{Impact wear apparatus}


The experimental apparatus has been designed to study impact wear between a SG tube sample and an AVB sample in water. Fig. 1 presents a schematic representation of the test machine. The stationary sample (AVB bar) is mounted on a very stiff support. The mobile sample (SG tube) is supported by two springs (stiffness $k=590 \mathrm{~N} / \mathrm{m}$ ) in the YZ-plane. Two shakers control the motion of the mobile sample.

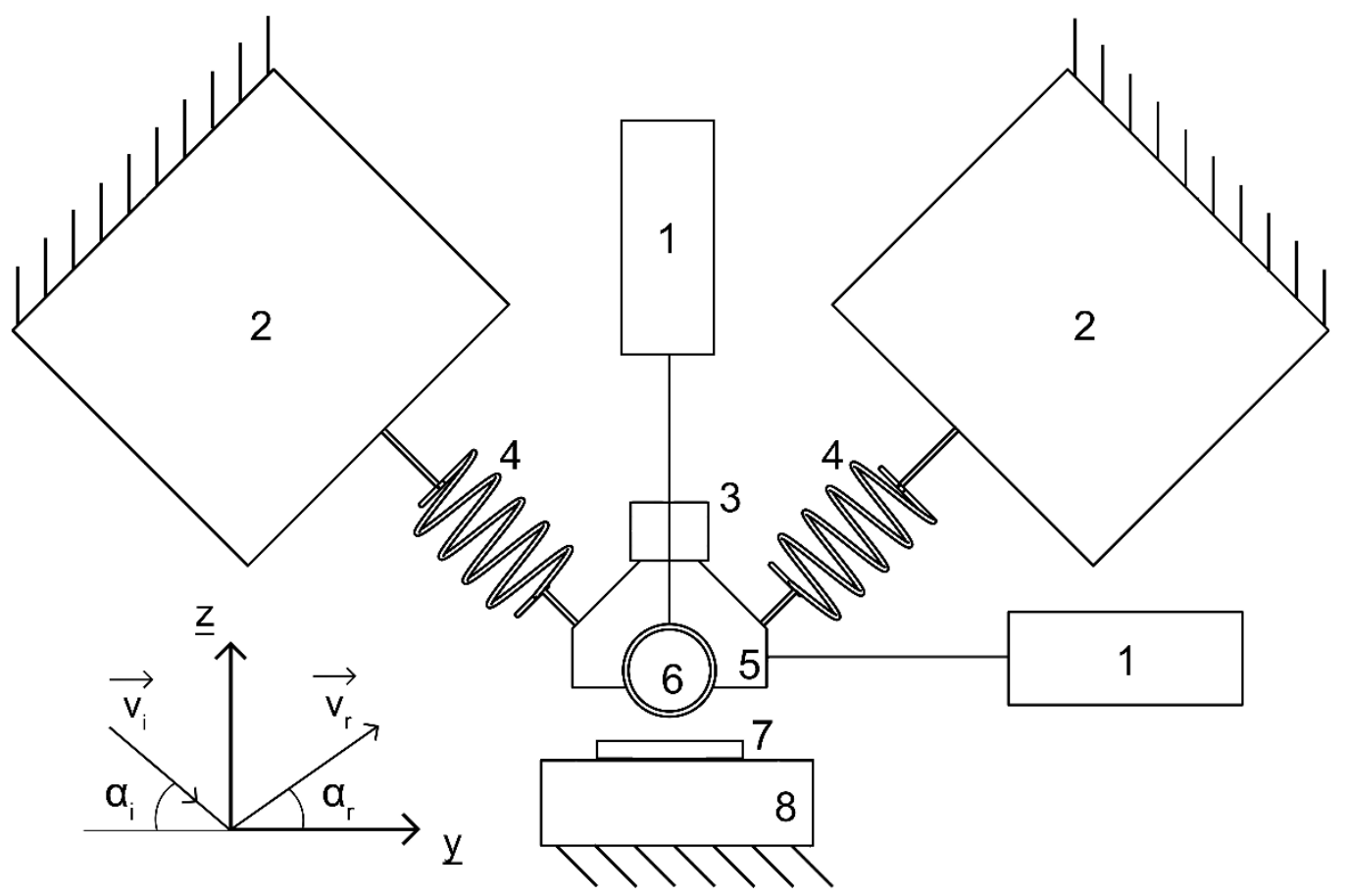

Fig. 1. Diagram of the impact wear test machine (1: Displacement sensors, 2: Shakers, 3: Loading mass, 4: Springs, 5: Tube holder, 6: SG Tube, 7: AVB holder and AVB sample, 8: Force transducer)

A 3-axis piezoelectric sensor is used to measure the normal and the tangential loads during impacts and two laser displacement sensors are used to measure the incidence and rebound parameters of each impact. The shakers excitation and the dynamic data acquisition are controlled by computer. Signals are recorded with a high sampling rate $(50 \mathrm{kHz})$ to obtain high quality measurements of the contact load time evolution during impacts.

A complete time acquisition of contact loads and displacements during the full length of the test is impossible due to storage space limitation. Therefore, signals are acquired during 2000 evenly distributed acquisition time windows of 1 second.

At the end of a wear test, the worn SG tube sample is analyzed with a microscope and an optical interferometer and wear volumes are measured.

\subsection{Wear specimens}

The stationary sample is a AISI 410s steel flat anti vibration bar sample (13 wt\% Cr, 1 wt\% Si, 1 wt\% $\mathrm{Mn}$ and $85 \mathrm{wt} \% \mathrm{Fe}$ ) of $12 \mathrm{~mm}$ width. The mobile sample is an Inconel 690 SG tube sample (31 wt\% Cr, 
$10 \mathrm{wt} \% \mathrm{Fe}$ and $59 \mathrm{wt} \% \mathrm{Fe}$ ) of $19.05 \mathrm{~mm}$ external diameter and $1.09 \mathrm{~mm}$ thickness. The samples used in this study are extracted from real components in order to obtain a good representativeness of the wear tests.

\subsection{Experimental conditions}

The influence of the impact dynamics is studied by varying the incidence angle $\alpha_{i}$ and the incidence energy $T_{i}$ of the impacts from a wear test to another. During each test, the incidence angle and the incidence kinetic energy are controlled to be constant. The standard test duration is $20 \mathrm{~h}$ and the excitation frequency $f$ is $20 \mathrm{~Hz}$ so that the total number of impacts is about 1.4 million. The tests are carried out at ambient temperature and in water. The water environment has been chosen to obtain a better representativeness of the wear tests to the PWR context of this study. The first tests campaign aims at studying the influence of the incidence angle on wear in the range $5^{\circ}-85^{\circ}$. During these tests, the incidence kinetic energy is controlled to be equal to $0.35 \mathrm{~mJ}$, corresponding to an incident velocity of 70 $\mathrm{mm} / \mathrm{s}$. The second tests campaign aims at studying the influence of the incidence energy on wear in the range $0.05 \mathrm{~mJ}-1 \mathrm{~mJ}$. During these tests, the incidence angle is controlled to be equal to $30^{\circ}$ from the horizontal.

Sweep tests have also been carried out in order to analyze more precisely the interdependence between impacts characteristics. During these tests, an incidence angle sweep is carried with a constant incident energy of $0.35 \mathrm{~mJ}$, an excitation frequency of $20 \mathrm{~Hz}$ and a test duration of $1600 \mathrm{~s}$. The incidence angle varies from $85^{\circ}$ at $\mathrm{t}=0 \mathrm{~s}$ to $5^{\circ}$ at $\mathrm{t}=1600 \mathrm{~s}$. The short duration of these tests allows to avoid the potential scattering of the measurements linked to the contact geometry modification as wear is generated during long tests. Similar sweep tests are carried with a varying incident energy from $0.05 \mathrm{~mJ}$ to $1 \mathrm{~mJ}$ and a constant incidence angle equal to $30^{\circ}$. The experimental results from the sweep tests are used to present the analysis of the impacts of Section 3.

\section{Statistical analysis of the impacts}

Impact wear is associated with dissipation. Several mechanical parameters are commonly used in the literature [1] to describe this dissipation. Among them one finds the restitution coefficient, impulse ratio, sliding distance, energy loss and in particular the tangential component of energy loss. Each of these parameters are deeply analyzed in the following in order to be correlated with wear in the next section.

\subsection{Impact characteristics}

Measured loads and displacements are processed to calculate the relevant parameters of impacts. The normal and tangential velocities before the impact $v_{i n}$ and $v_{i t}$ and after the impact $v_{r n}$ and $v_{r t}$ are deduced from displacements. The incidence angle $\alpha_{i}$ and the rebound angle $\alpha_{r}$ of the mobile sample are calculated as follows: 


$$
\begin{aligned}
& \alpha_{i}=\tan ^{-1}\left|\frac{v_{i n}}{v_{i t}}\right| \\
& \alpha_{r}=\tan ^{-1}\left|\frac{v_{r n}}{v_{r t}}\right|
\end{aligned}
$$

The convention adopted in this study defines that the incidence angle is $0^{\circ}$ for pure horizontal incidence and $90^{\circ}$ for normal impacts. The tangential and the normal components of the energy loss $T_{L}$ during an impact are also calculated from the measured velocities:

$$
\begin{aligned}
& T_{L t}=\frac{1}{2} m\left(v_{i t}^{2}-v_{r t}^{2}\right) \\
& T_{L n}=\frac{1}{2} m\left(v_{i n}^{2}-v_{r n}^{2}\right)
\end{aligned}
$$

and the total loss is $T_{L}=T_{L t}+T_{L n}$. The dimensionless energy loss $T_{L}^{*}$ is defined by $T_{L}^{*}=T_{L} / T_{i}$ where $T_{i}$ is the incident kinetic energy of the projectile.

The restitution coefficient $e$ is identified from normal velocities:

$$
e=-\frac{v_{r n}}{v_{i n}}
$$

The normal and tangential impulses are calculated by integrating the measured loads over the contact duration,

$$
\begin{aligned}
& P_{t}=\int_{t_{i t}}^{t_{r t}} F_{t}(t) d t=m\left(v_{r t}-v_{i t}\right) \\
& P_{n}=\int_{t_{i n}}^{t_{r n}} F_{n}(t) d t=m\left(v_{r t}-v_{i t}\right)
\end{aligned}
$$

and an impulse ratio $\mu$ is introduced:

$$
\mu=\frac{P_{t}}{P_{n}}
$$

The sliding distance $l_{s}$ during an impact is calculated from the measurement of the tangential displacement between the beginning and the end of the impact:

$$
l_{s}=\left|D_{t}\left(t_{r t}\right)-D_{t}\left(t_{i t}\right)\right|
$$

\subsection{Restitution during impacts}

Fig. 2 displays restitution coefficient $e$ versus incidence angle $\alpha_{i}$ for data measured during a sweep test. Each point of the cloud corresponds to a single impact. 32000 impacts are performed during a sweep test. The range of abscissa values is divided in ten equal parts. Error bars are estimated for each part and correspond to standard deviations of abscissa values for horizontal bars and ordinate values for vertical bars. It can be observed that the restitution coefficient slightly increases from 0.85 to 0.95 when incidence angle increases from $5^{\circ}$ to $85^{\circ}$. The more grazing the incidence angle is, the more scattered the experimental values of restitution coefficient are. This can be explained as small incidence angles lead to lower normal velocities and larger measurement errors. It can also be due to a more significant 
influence of the surface topography on the rebound characteristics at small angles. The dashed black line corresponds to a linear fit defined by:

$$
e\left(\alpha_{i}\right)=1.310^{-3} \alpha_{i}+0.83
$$

where $\alpha_{i}$ is in degrees. The observed values of restitution coefficient are in the same order of magnitude of previous observations carried in the same incidence velocity range [32]. A study performed with the same impact test machine in dry environment shows that the restitution coefficient has slightly lower values in air than in water and ranges from 0.6 to 0.9 depending on the incidence angle [33].

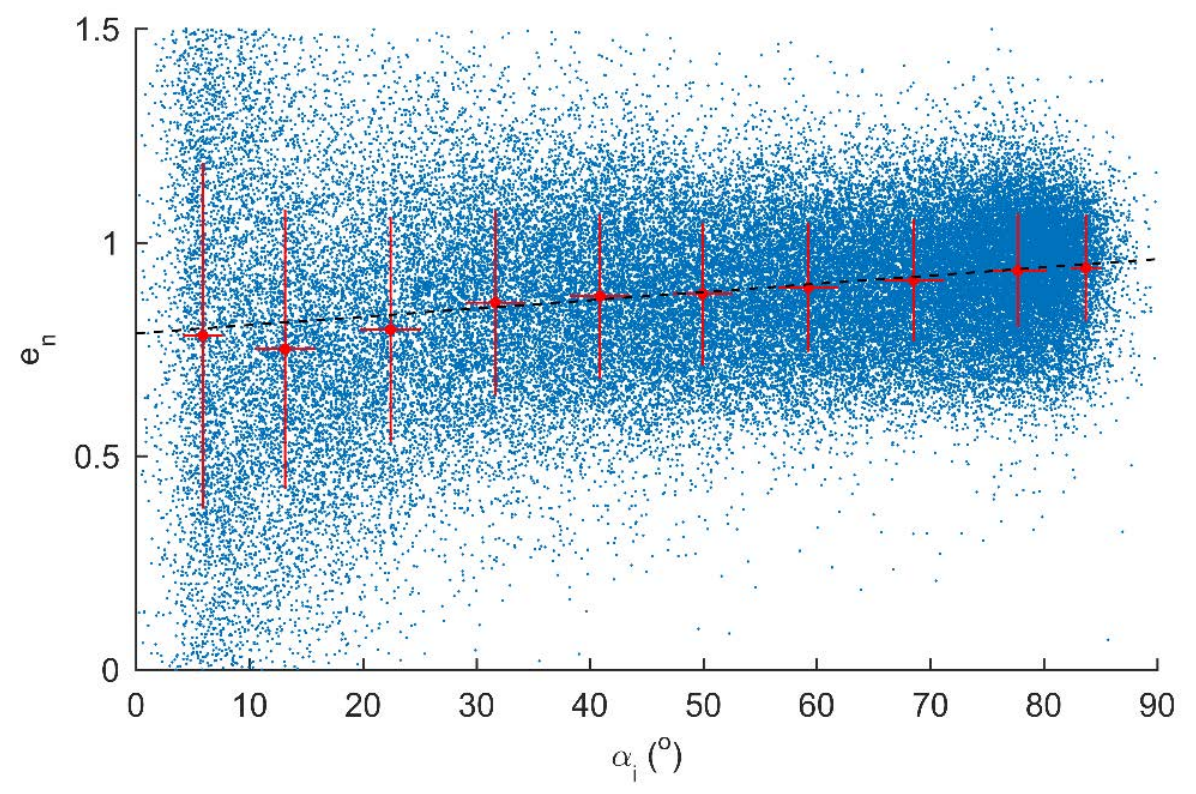

Fig. 2. Restitution coefficient vs incidence angle during impacts in water environment. Cloud: experimental data; broken black curve: linear fit.

Experimental results from energy sweep tests show that the restitution coefficient is constant with the incident energy in the range $0.05 \mathrm{~mJ}-1 \mathrm{~mJ}$.

\subsection{Friction during impacts}

Fig. 3 displays the experimental impulse ratio $\mu$ defined in Eq. (8) versus incidence angle $\alpha_{i}$ for data measured during a sweep test. The dots color from blue to yellow corresponds to the rebound angle for small rebound angles (blue) to normal rebound (yellow). The impulse ratio decreases from 0.4 to 0.1 and the rebound angle increases from $0^{\circ}$ to $90^{\circ}$ when the incidence angle increases from $0^{\circ}$ to $85^{\circ}$. The impulse ratio follows a piecewise linear decrease with a slope depending on the incidence angle range:

$$
\begin{array}{lc}
\mu=-2.110^{-3} \alpha+0.41, & 0<\alpha<65^{\circ} \\
\mu=-6.810^{-3} \alpha+0.71, & 65<\alpha<85^{\circ}
\end{array}
$$

In the range of incidence angle $0^{\circ}-65^{\circ}$, the rebound angle increases from $0^{\circ}$ to $65^{\circ}$. In the range $65^{\circ}$ - $85^{\circ}$, the rebound angle is constant and equal to $90^{\circ}$. 


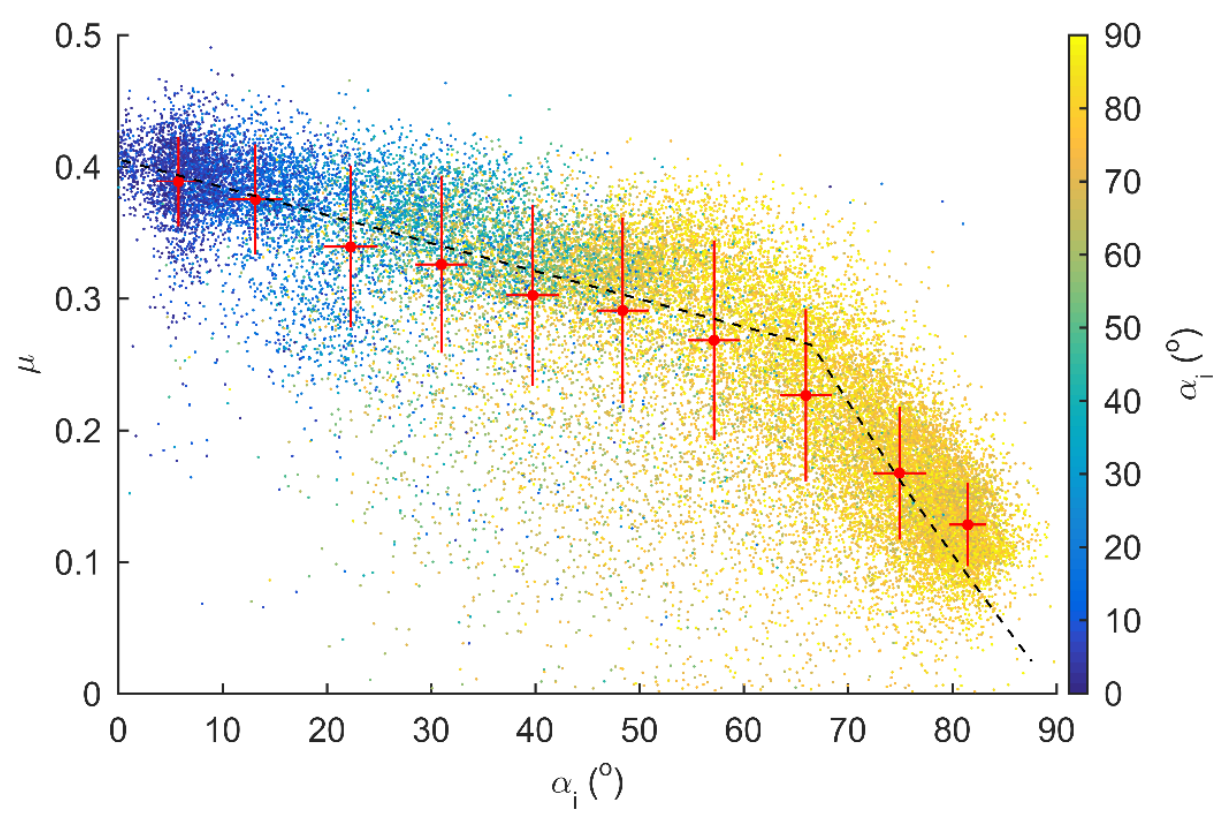

Fig. 3. Impulse ratio vs incidence angle during impacts in water environment. Cloud: experimental data; black curve computed from Eq. (16).

The critical impulse ratio $\mu_{c}$ defined by Brach [22] is introduced. In our case it is given by:

$$
\mu_{c}=\frac{1}{1+e} \frac{1}{\tan \alpha_{i}}
$$

This critical impulse ratio corresponds to the upper bound of an impact impulse ratio. It is interesting to note that this ratio corresponds to the slip factor $f_{\text {Engel }}$ introduced by Engel [2] in a different way but with the same meaning:

$$
f_{\text {Engel }}<2 \Leftrightarrow \mu>\mu_{c}
$$

If $\mu<\mu_{c}$, there is sliding during all the impact and therefore $\mu$ is equal to the usual kinetic friction coefficient $\mu_{k}$. The case $\mu=\mu_{c}$ corresponds to impacts for which the tangential velocity $v_{r t}$ falls to zero in the contact phase. Following Eq. (2), this case induces normal rebound angles.

A critical incidence angle $\alpha_{c}$ is introduced and corresponds to the threshold between the two friction regimes described previously:

$$
\alpha_{c}=\tan ^{-1}\left(\frac{1}{\mu_{k}} \frac{1}{1+e}\right)
$$

The dotted black curve in Fig. 3 corresponds to the following model:

$$
\mu\left(\alpha_{i}\right)= \begin{cases}\mu_{k}\left(\alpha_{i}\right), & 0^{\circ} \leq \alpha_{i} \leq \alpha_{c} \\ \mu_{c}\left(\alpha_{i}\right), & \alpha_{i} \geq \alpha_{c}\end{cases}
$$


where $\mu_{c}$ is calculated from Eq. (13) with the value of restitution coefficient from Eq. (10), the critical incidence angle $\alpha_{c}$ is calculated from Eq. (15) and equals $\alpha_{c}=65^{\circ}$, and $\mu_{k}$ corresponds to the linear fit of the experimental values of Eq. (11).

A good correlation is observed between the experimental results and the model. In particular, the critical incidence angle $\alpha_{c}$ is well predicted and the evolution of the impulse ratio in the case $\alpha_{i} \geq$ $\alpha_{c}$ is consistent with the critical impulse ratio defined by Brach [22] and Engel [2] as well as their description of the rebound behavior in this range: normal rebound angles are observed in the case $\mu=$ $\mu_{c}$.

Experimental results from energy sweep tests show that the impulse ratio is constant with the incident energy in the range $0.05 \mathrm{~mJ}-1 \mathrm{~mJ}$.

\subsection{Energy loss during impacts}

Fig. 4 shows total dimensionless energy loss $T_{L}^{*}$ and tangential energy loss $\mathrm{T}_{\mathrm{Lt}}^{*}$ during impacts in water environment versus incidence angle $\alpha_{i}$. These energy losses are calculated for each impact from the measurements of incidence and rebound velocities using Eq. (3) and Eq. (4). The mean values of the total dimensionless energy loss $T_{L}^{*}$ increase from 0 to 0.5 when incidence angle increases from $0^{\circ}$ to $37^{\circ}$. A maximum of total energy loss is observed at the incidence angle of $37^{\circ}$. The total energy loss decreases in the range of incidence angle $37^{\circ}-80^{\circ}$ to reach 0.2 at $80^{\circ}$. A similar evolution is observed for the tangential component of the energy loss $T_{L t}^{*}$ versus incidence angle: the experimental values increase from 0 to 0.43 in the range $0^{\circ}-37^{\circ}$ and decrease from 0.43 to 0 in the range $37^{\circ}-90^{\circ}$.
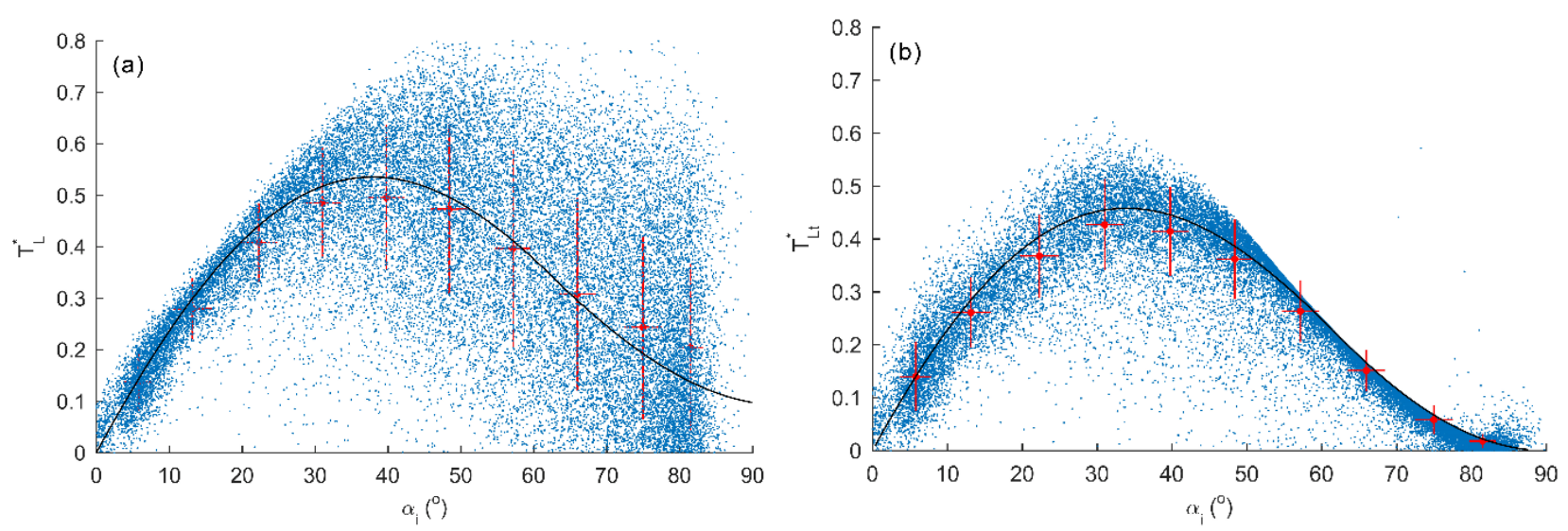

Fig. 4. (a) Total dimensionless energy loss $T_{L}^{*}$ versus incidence angle $\alpha_{i}$ during impacts in water environment. (b) Tangential dimensionless energy loss $T_{L t}^{*}$ versus incidence angle $\alpha_{i}$ during impacts in water environment. Cloud: experimental data; solid black line respectively computed from Eq. (17) and Eq. (18).

Using Eqs. (1-7), the dimensionless energy loss during impacts $T_{L}^{*}$ and its tangential component $T_{L t}^{*}$ can be expressed as a function of incidence angle $\alpha_{i}$, and the common coefficients: restitution coefficient $e$ and impulse ratio $\mu$ [22]. This formulation allows to eliminate rebound characteristics of impacts which are unknowns: 


$$
\begin{gathered}
T_{L}^{*}\left(\alpha_{i}, e, \mu\right)=\left(T_{L t}+T_{L n}\right) / T_{i}=\sin ^{2} \alpha_{i}(1+e)\left[1-e+\frac{2 \mu}{\tan \alpha_{i}}-\mu^{2}(1+e)\right] \\
T_{L t}^{*}\left(\alpha_{i}, e, \mu\right)=T_{L t} / T_{i}=\sin ^{2} \alpha_{i}(1+e)\left[\frac{2 \mu}{\tan \alpha_{i}}-\mu^{2}(1+e)\right]
\end{gathered}
$$

The solid black curves in Fig. 4 are calculated from Eq. (17) and Eq. (18) in which the values of restitution coefficient $e$ and impulse ratio $\mu$ are calculated with respectively Eq. (10) and Eq. (16). A good correlation is observed between the mean values of the experimental results and the formulation of the energy losses defined by Eq. (17) and Eq. (18). These results extend the validity of the formulation originally proposed for single erosive particle by Brach $[22,23]$ to the case of percussive multi-asperities contacts. Nevertheless, the total experimental energy loss is much scattered in the range $37^{\circ}-80^{\circ}$ which is related to the scattering of the normal energy loss. This scattering may be related to a more significant influence of the asperity-asperity contact characteristics in this range of incident angles.

\subsection{Sliding distance during impacts}

The sliding distance $l_{s}$ during impacts is estimated by Eq. (9). Fig. 5 displays experimental sliding distance versus incidence angle during a sweep test in water environment. The sliding distance decreases from $25 \mu \mathrm{m}$ to $2 \mu \mathrm{m}$ when the incidence angle increases from $0^{\circ}$ to $85^{\circ}$ in a quasi linear evolution. The dotted line corresponds to a linear fit of the experimental values. Fig. 6 displays sliding distance during impacts versus incident energy for several wear tests carried at incident energies ranging from $0.1 \mathrm{~mJ}$ to $1.2 \mathrm{~mJ}$ and at a constant incidence angle equal to $30^{\circ}$. The experimental sliding distance increases from 0 to $27 \mu \mathrm{m}$ as the incident energy increases from 0 to $1.1 \mathrm{~mJ}$.

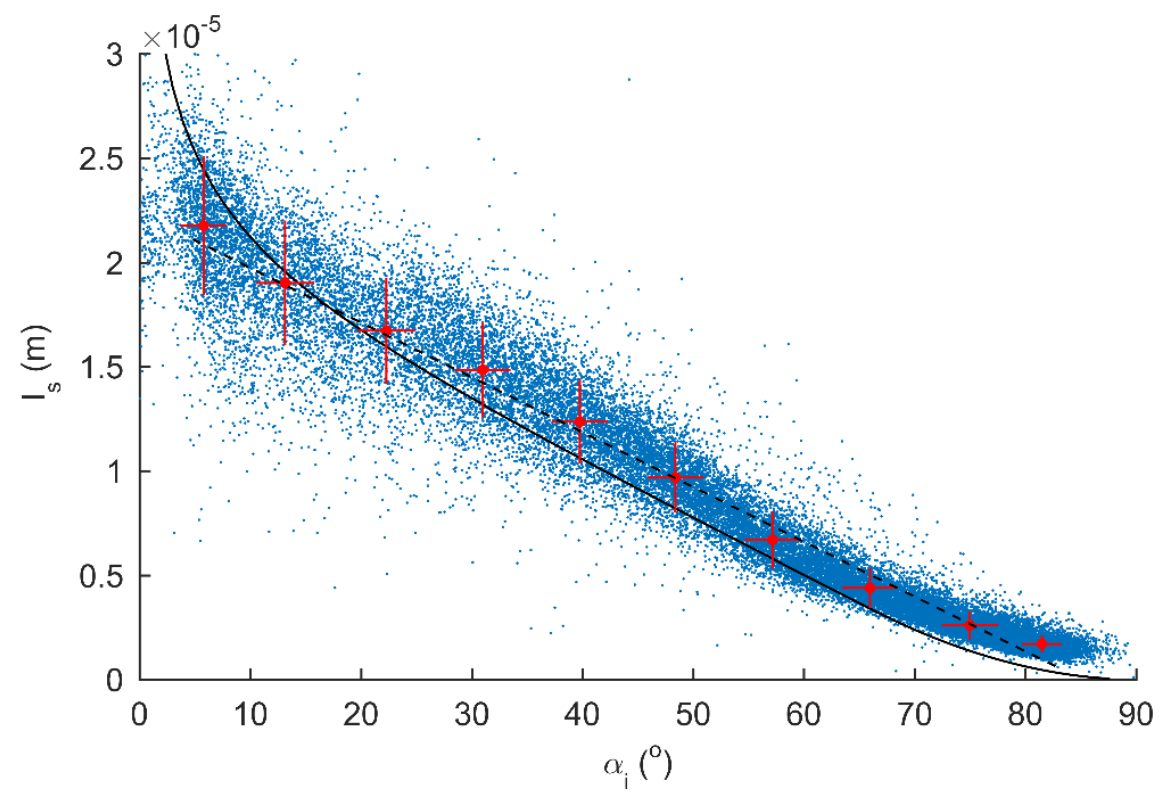

Fig. 5. Sliding distance versus incidence angle $\alpha_{i}$ during impacts in water environment. Cloud: experimental data; solid line computed from Eq. (26); dotted line: linear fit of the experimental values. 


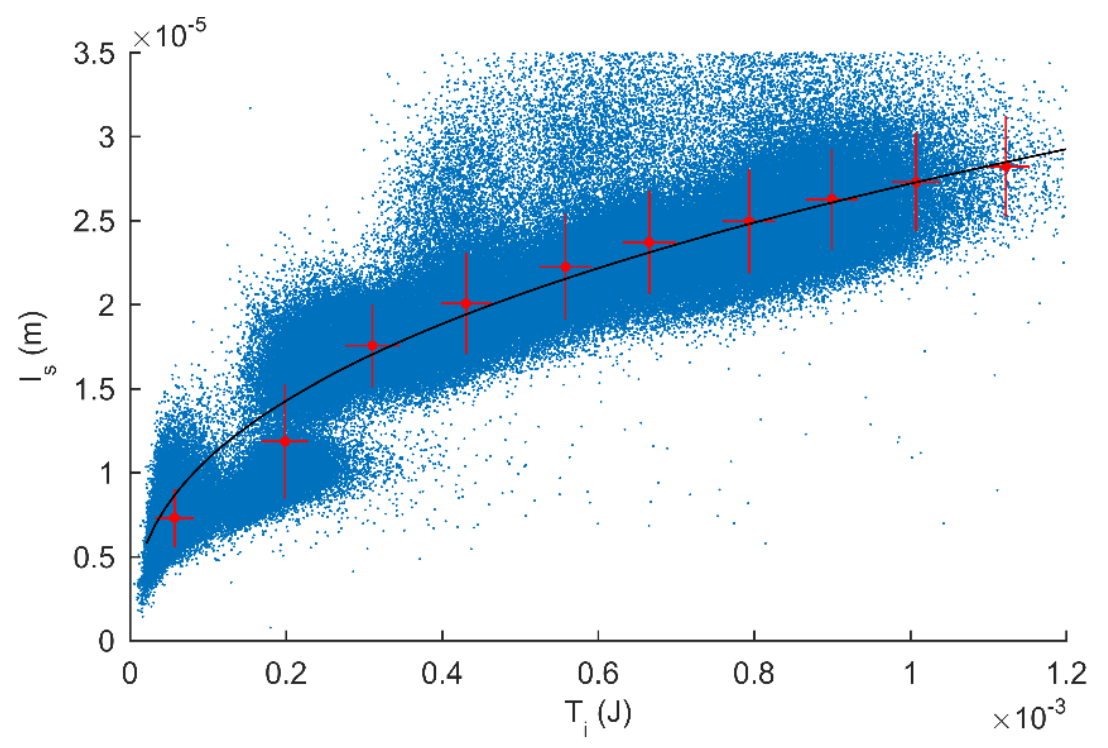

Fig. 6. Sliding distance versus incidence energy $T_{i}$ during impacts in water environment at constant incidence angle equal to $30^{\circ}$. Cloud: experimental data; solid black line computed from Eq. (26).

In numerous impact wear studies, the sliding distance during the impacts is considered as a parameter with a significant influence on wear [7,9,34-36]. But in most cases, the sliding distance during impacts is neither measured nor predicted but is assumed to be proportional to the impact duration. The sliding distance during impacts and the impact duration are two unknowns and not input parameters in an impact problem. A model of the sliding distance during impact $l_{s}$ defined in Eq. (9) is proposed in order to express it as a function of incident impact characteristics only, material properties and the usual coefficients: restitution coefficient $e$ and impulse ratio $\mu$. The following assumptions are adopted:

1. The sliding velocity varies linearly during the impact.

2. There is no stick period during the contact.

3. The normal and tangential contact loads are approximated by a sinusoidal evolution:

$$
\begin{aligned}
& F_{t}=F_{t m} \sin \left(\frac{\pi}{d_{t}} t\right) \\
& F_{n}=F_{n m} \sin \left(\frac{\pi}{d_{n}} t\right)
\end{aligned}
$$

where $F_{t m}$ and $F_{n m}$ are the maximum values of tangential and normal contact loads during impacts.

4. The kinetic friction coefficient $\mu_{k}$ is defined by:

$$
\mu_{k}=\frac{F_{t m}}{F_{n m}}
$$

Using Eq. (9) and assumptions 1. and 2., we obtain:

$$
l_{s}=d_{t} \frac{\left(v_{i t}+v_{r t}\right)}{2}
$$


where the tangential impact duration $d_{t}$ is defined as the duration of application of tangential load during impact.

Combining Eq. (1), (5), (6), (7), (8), we obtain:

$$
l_{s}=d_{t} v_{i} \sin \alpha_{i}\left[\frac{1}{\tan \alpha_{i}}-\frac{\mu}{2}(1+e)\right]
$$

In the case $\alpha_{i} \leq \alpha_{c}$, sliding occurs during all the contact, therefore $d_{t}=d_{n}$ and $\mu=\mu_{k}$. In the case $\alpha_{i} \geq \alpha_{c}$, a phase of sliding is followed by a phase during which $F_{t}=0$ and $F_{n} \neq 0$, therefore $d_{t} \neq$ $d_{n}, v_{r t}=0$ and $\mu=\mu_{c}$. It follows:

$$
l_{s}=\left\{\begin{aligned}
& d_{n} v_{i} \sin \alpha_{i}\left[\frac{1}{\tan \alpha_{i}}-\frac{\mu_{k}}{2}(1+e)\right], \alpha<\alpha_{\mathrm{c}} \\
& d_{t} \frac{v_{i t}}{2}=d_{n} v_{i} \cos \alpha_{i} \frac{1}{2 \mu_{k}(1+e) \tan \alpha_{i}}, \quad \alpha>\alpha_{\mathrm{c}}
\end{aligned}\right.
$$

The normal contact duration $d_{n}$ is calculated following the case of an elastic shock between asperities considered as spheres [37]:

$$
d_{n}=2.87 \frac{m_{a}^{2 / 5}}{\left(\beta E^{* 2} v_{i} \sin \alpha_{i}\right)^{1 / 5}}
$$

where $m_{a}$ is the apparent mass seen by one contact asperity, $\beta$ the radius of curvature of the asperity and $E^{*}$ the equivalent Young modulus of materials.

Finally, it leads to:

$$
l_{s}=\left\{\begin{array}{r}
2.87 \frac{m_{a}^{2 / 5}}{\left(\beta E^{* 2}\right)^{1 / 5}}\left(v_{i} \sin \alpha_{i}\right)^{4 / 5}\left[\frac{1}{\tan \alpha_{i}}-\frac{\mu_{k}}{2}(1+e)\right], \alpha<\alpha_{\mathrm{c}} \\
2.87 \frac{m_{a}^{2 / 5}}{\left(\beta E^{* 2}\right)^{1 / 5}}\left(v_{i} \sin \alpha_{i}\right)^{4 / 5} \frac{1}{2 \mu_{k}(1+e) \tan ^{2} \alpha_{i}}, \alpha>\alpha_{\mathrm{c}}
\end{array}\right.
$$

The solid black curves in Fig. 5 and in Fig. 6 correspond to this model with equivalent Young modulus $E^{*}=115 \mathrm{GPa}$, incident velocity $v_{i}=0.07 \mathrm{~m} / \mathrm{s}$, asperity radius of curvature $\beta=100 \mu \mathrm{m}$ and apparent mass respectively $m_{a}=0.02 \mathrm{~kg}$ and $m_{a}=0.05 \mathrm{~kg}$. This difference of apparent mass seen by a contact asperity is related to a difference of contact asperities number during the two categories of tests carried and analyzed to draw Fig. 5 and Fig. 6. A good correlation is observed between the experimental values of sliding distance and the proposed model which tends to confirm the validity of this approach.

\subsection{Scattering of measurements during long wear tests}

Fig. 7 displays impulse ratio versus incidence angle for long wear tests during different time sequences selected in the complete duration of the tests. From the top left corner to bottom right corner, the sequences $t=0-30 \min (b), t=0-1 h(c), t=0-2 h(d), t=0-4 h(e), t=0-8 h(f)$, and $t=0-16 h$ of each 
test are represented. Each color corresponds to a specific test with a constant incidence angle. The dotted black curve is computed from Eq. (16). Same evolutions of impact characteristics versus incidence angle and incident energy are observed during long wear tests with a progressive scattering of the measurements from the beginning of the test to the end. During the beginning of the long wear tests $(t=0-1 \mathrm{~h})$, the measurements are not substantially scattered and are well predicted by the model proposed in Eq. (16). The scattering progressively increases for the majority of the tests between $t=1 \mathrm{~h}$ and $t=20 \mathrm{~h}$. In the specific case of Fig. 7, the impulse ratio decreases with time for the majority of the tests. This scattering of measurements with time seems to be linked to the contact geometry modification as wear is generated during long wear tests.
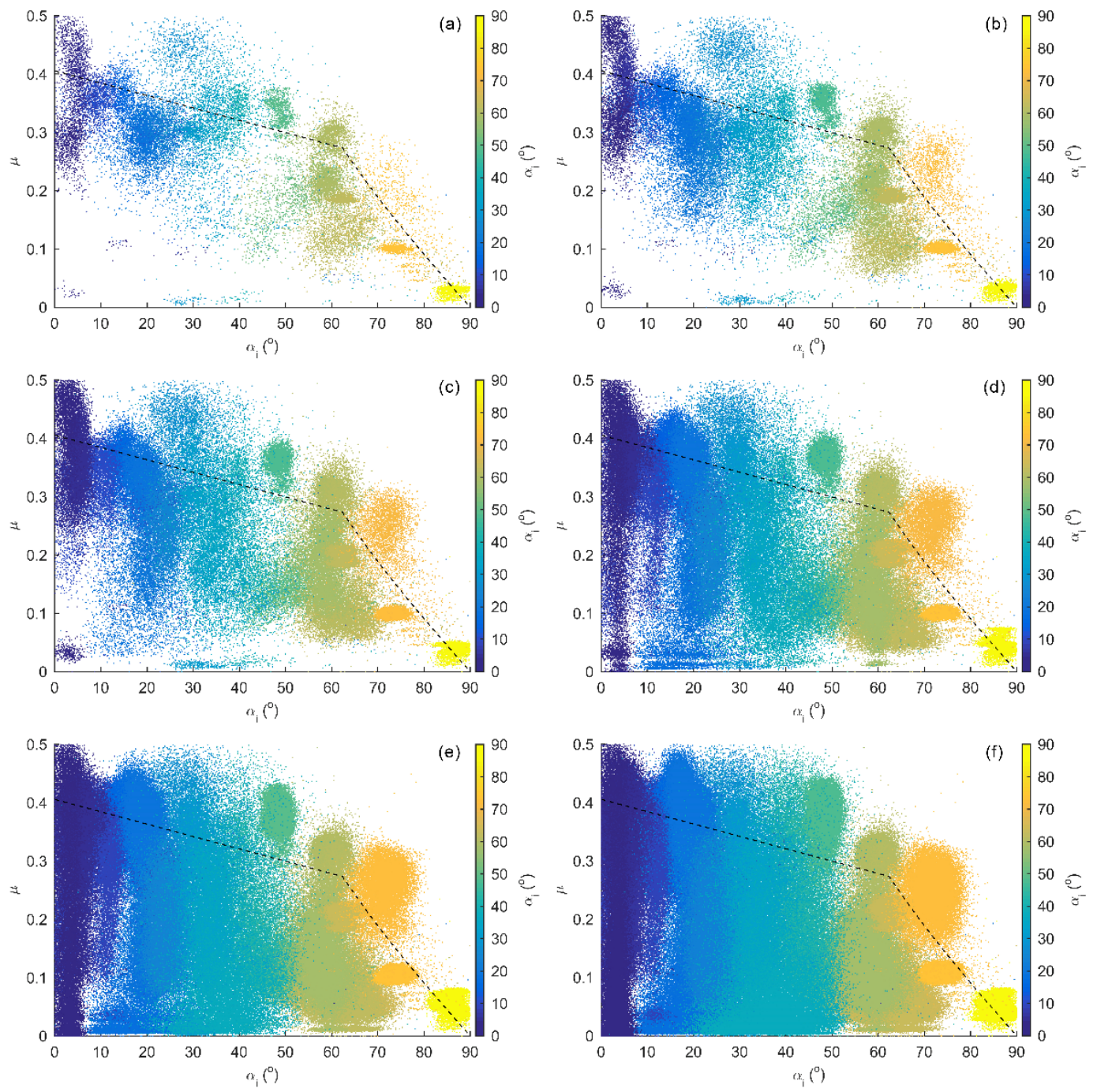

Fig. 7. Impulse ratio $\mu$ versus incidence angle $\alpha_{i}$ during long tests wear in water environment. Cloud: experimental data; black line computed from Eq. (16). (a) $t=0-30 \mathrm{~min}$. (b) $t=0-1 \mathrm{~h}$. (c) $t=0-2 \mathrm{~h}$. (d) $t=0-4 \mathrm{~h}$. (e) $t=0-8 h$. (f) $t=0-16 h$. 


\section{Wear analysis}

\subsection{Wear scars}

At the end of each test, wear is observed on the SG tube and to a lesser extent on the AVB sample. Only SG tube wear is considered in the following as it constitutes the critical industrial issue. Fig. 8 displays a scanning electron microscope (SEM) image (a) and an interferometry image (b) of a typical wear scar obtained after 20h of impacts in water environment. The global shape of the wear scar is triangular as the geometry of the contact is cylinder-plane with a small default of parallelism. The worn surface is globally smoother than the intact surface but presents also large cavities of length $500 \mu \mathrm{m}$ and width $100 \mu \mathrm{m}$. Fig. 9 displays a magnification of the SEM image of Fig. 8. Numerous scratches of length 10-20 $\mu \mathrm{m}$ and width 1-2 $\mu \mathrm{m}$ are visible on the worn surface. This could correspond to the passage of an abrasive asperity or particle on the sample surface during an impact. It is interesting to note that the length of the observed scratches is in the same order of magnitude as the sliding distance during the impacts.

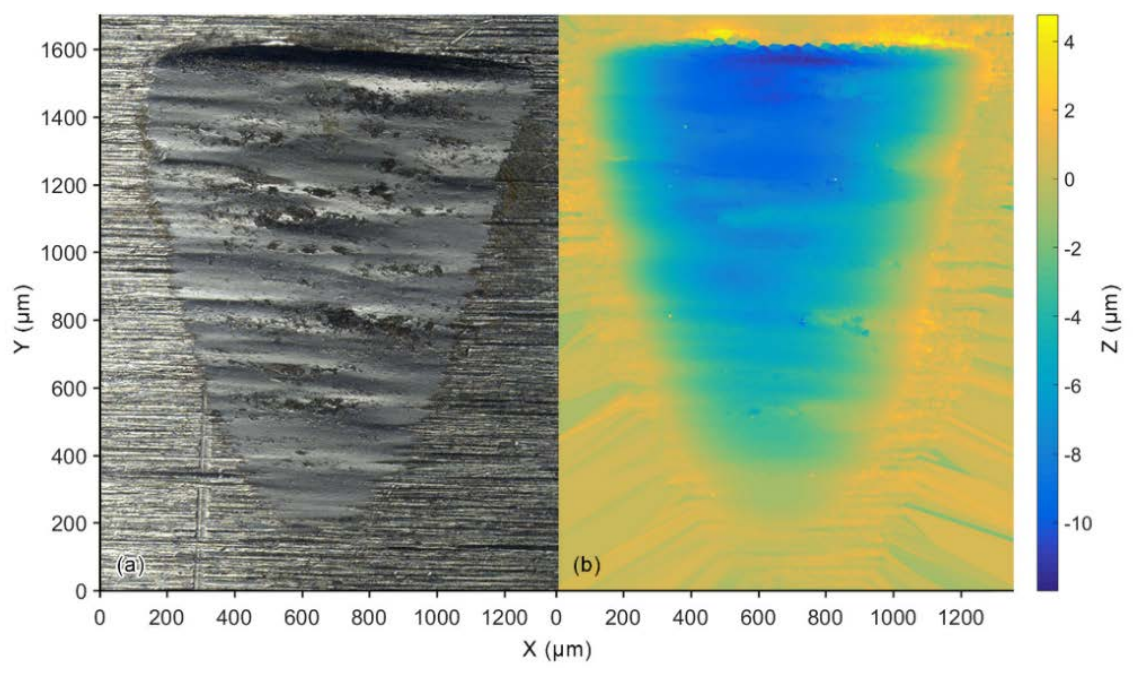

Fig. 8. Complete tube wear scar images. (a) SEM image. (b) Interferometry image.

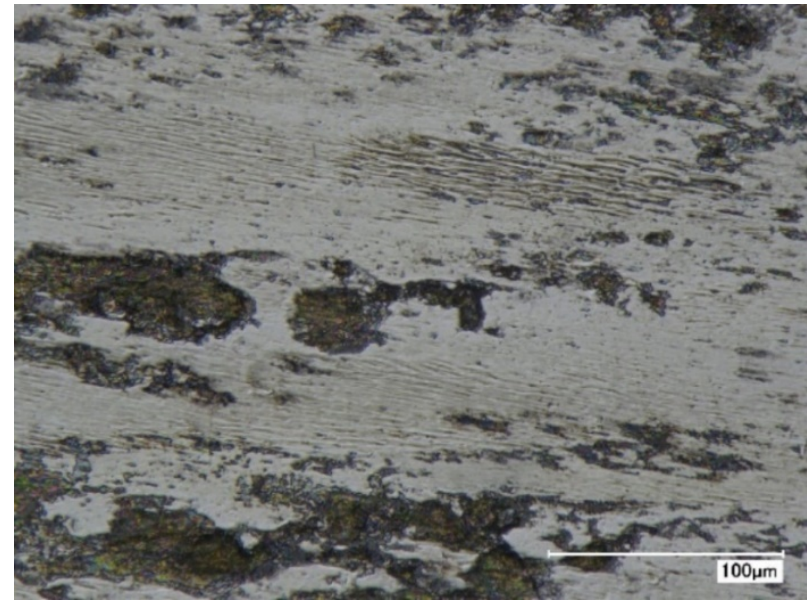

Fig. 9. Magnified tube wear scar SEM image. 


\subsection{Wear roughness}

The change of tube surface roughness properties between the undamaged and the worn surface visually observed in Fig. 8 and Fig. 9 is completed by an extensive analysis of the worn surface roughness parameters. For each test, the topography of the worn surface is measured using an interferometer and computed in order to obtain a mean value of the roughness parameter $R_{q}$. Fig. 10 displays the value of the impulse ratio $\mu_{\text {end }}$ at the end of each test versus the roughness parameter $R_{q}$. The impulse ratio increases from 0 to 0.45 when $R_{q}$ increases from 0.22 to 1.58. In other words, a smooth worn surface leads to small values of impulse ratio. This result explains the measurements scattering observed in the previous section: during long wear tests, wear is generated, contact surfaces roughness decreases and therefore the impulse ratio decreases.

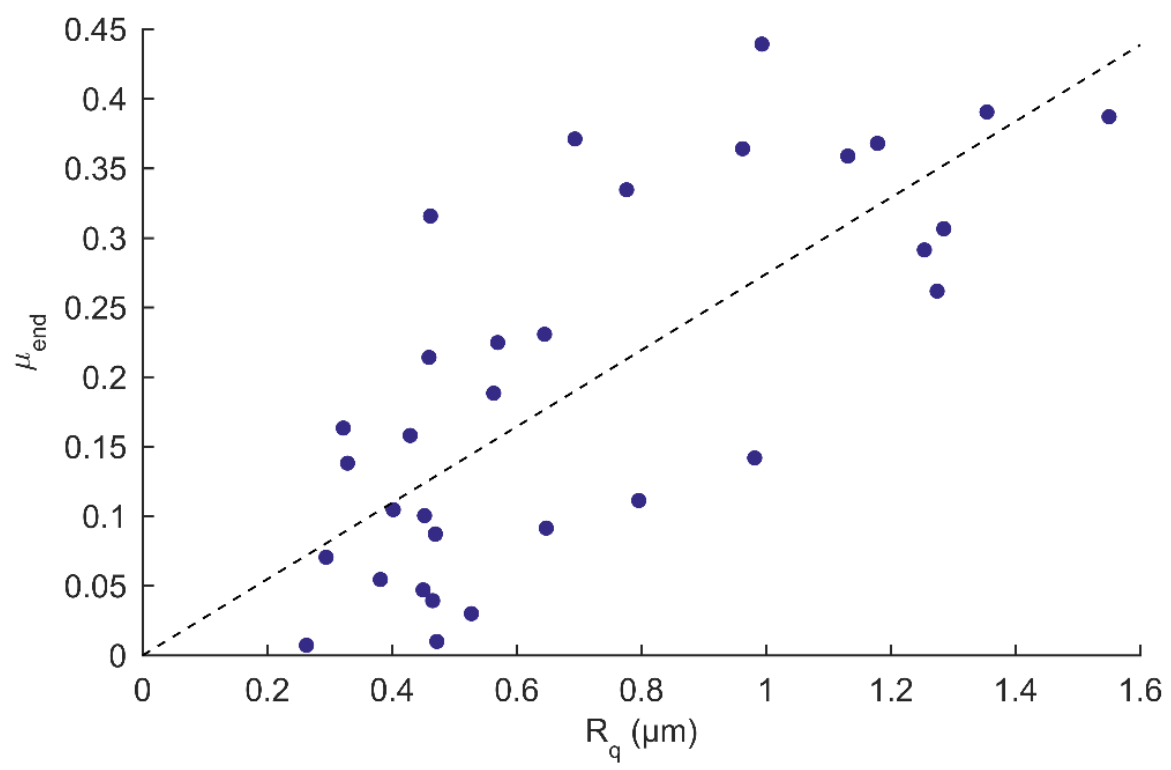

Fig. 10. Impulse ratio at the end of the wear test versus $R_{q}$ roughness parameter of the wear scar; dotted black line: linear fit.

\subsection{Wear volume}

Fig. 11 displays experimental wear volume per impact versus average incidence angle for each long wear test carried out in water environment at constant incident energy. Wear increases from 3 to $5 \mu m^{3}$ per impact between $5^{\circ}$ and $20^{\circ}$ and decreases from 5 to $0 \mu \mathrm{m}^{3}$ between $20^{\circ}$ and $90^{\circ}$. Wear is maximum at $20^{\circ}$ which is consistent with other studies on low-loaded percussive impacts [38-40]. The existence of a maximum of wear at a certain incidence angle is often observed in particle erosion studies $[13,14,18]$. This similarity shows that the same processes of material removal could happen for these two types of impacts. The validity of this argument is supported by the fact that the size and the energy of the projectile is at the same order of magnitude for both cases: particle with high velocity but light mass for particle erosion and contact asperities with low velocity and high mass for low-loaded percussive impacts. 


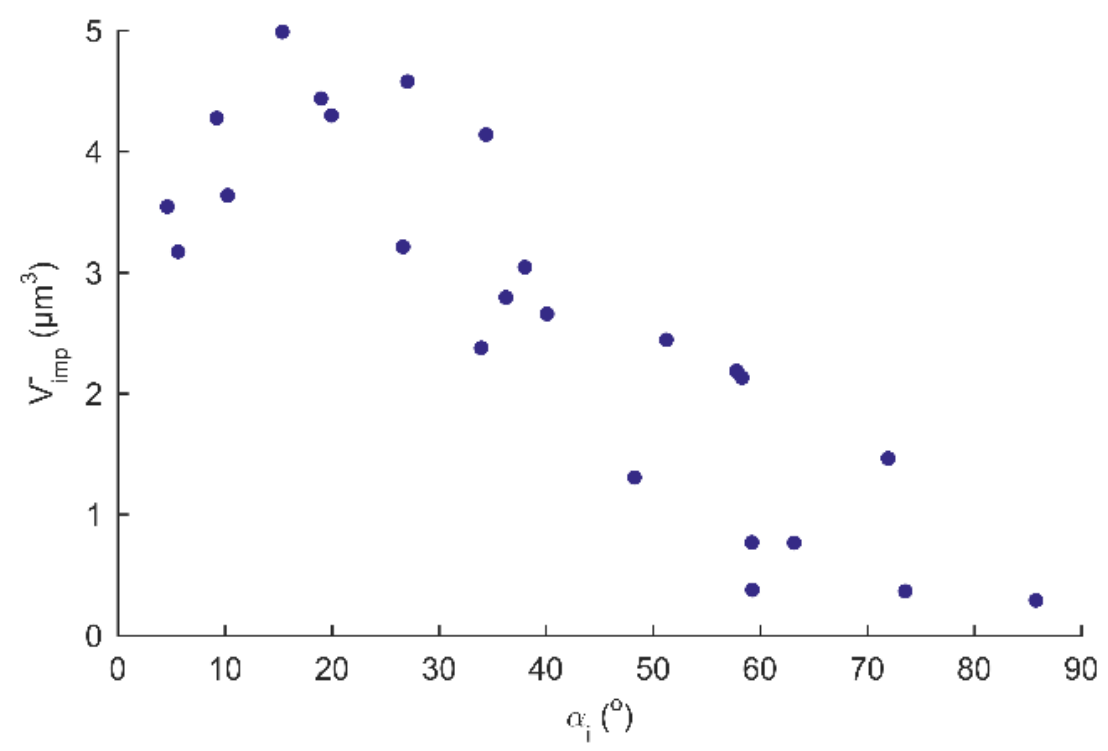

Fig. 11. Wear volume per impact versus incidence angle.

Fig. 12 displays experimental wear volume per impact versus average energy loss during impact for each long wear test carried out in water environment at constant incidence angle equal to $30^{\circ}$. Wear volume increases linearly with the energy loss from 0 to $12 \mu \mathrm{m}^{3}$ in the range $0-0.4 \mathrm{~mJ}$. The dotted black curve is a linear fit of the experimental values. The observed proportionality between wear volume and energy loss during an impact is consistent with numerous studies [2,5,13,15,41-46]. It shows that a constant proportion of the energy loss is used to material removal in the range $0-0.4 \mathrm{~mJ}$.

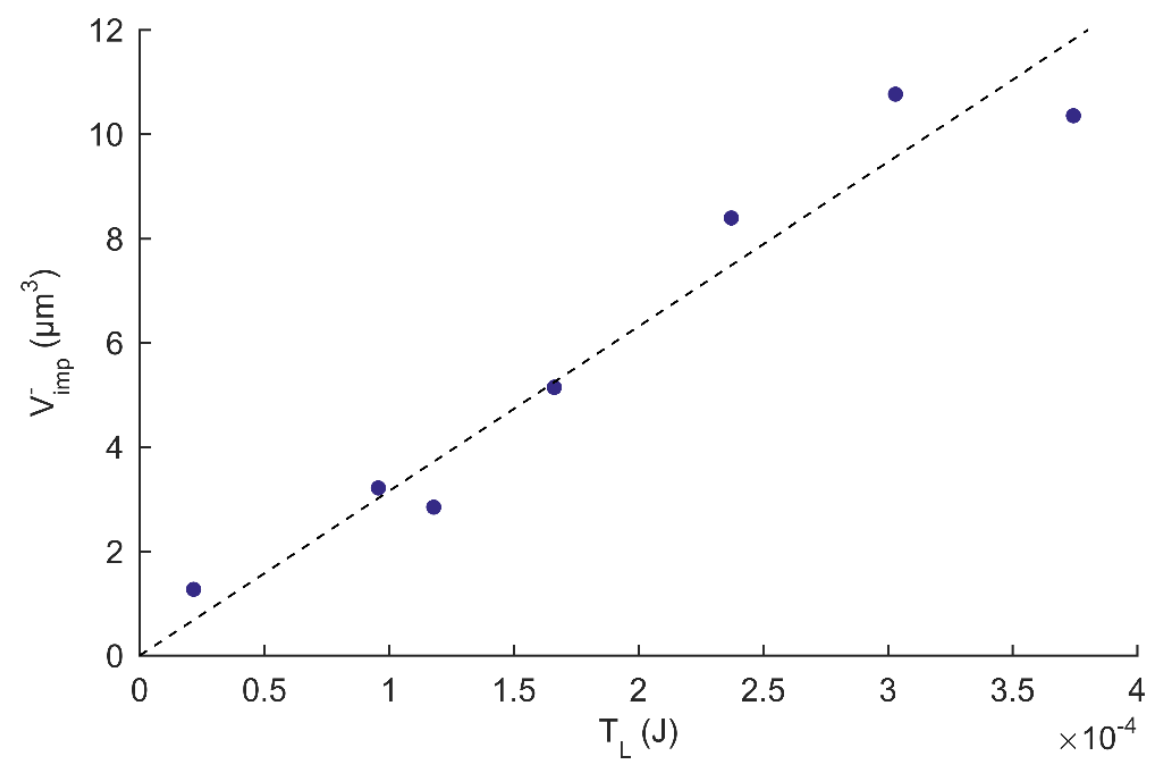

Fig. 12. Wear volume per impact versus energy loss at constant incidence angle equal to $30^{\circ}$; dotted black line: linear fit. 


\subsection{Discussion on energy}

Fig. 13 displays wear volume per impact $V_{i m p}^{-}$versus energy loss per impact $T_{L}$ and mean incidence angle during the wear test $\alpha_{i}$ for each long wear test carried out in water environment. The color of the experimental points also corresponds to the incidence angle $\alpha_{i}$. The four black curves correspond to four linear fits of the experimental values whose incidence angle ranges respectively from 5 to $15^{\circ}$, from 25 to $35^{\circ}$, from 50 to $60^{\circ}$ and from 75 to $85^{\circ}$. For each of these ranges of incidence angle, a good proportionality is observed between wear volume $V_{i m p}^{-}$and energy loss $T_{L}$. The proportionality coefficient $K$ between wear volume and energy loss is different for each of these ranges and depends on the incidence angle:

$$
V_{i m p}^{-}=K\left(\alpha_{i}\right) T_{L}
$$

A similar proportionality between wear volume and energy loss is observed for impacts in dry environment but with a proportionality coefficient independent of the incidence angle [33]. It shows that energy loss alone is not sufficient to predict impact wear volume in water environment: it depends both on energy loss and incidence angle. Therefore, the severest case for wear would be at low incidence angle and high energy loss. As energy loss is proportional to incident energy (Eq. (17)), the severest case for wear is at low incidence angle equal and high incident energy.

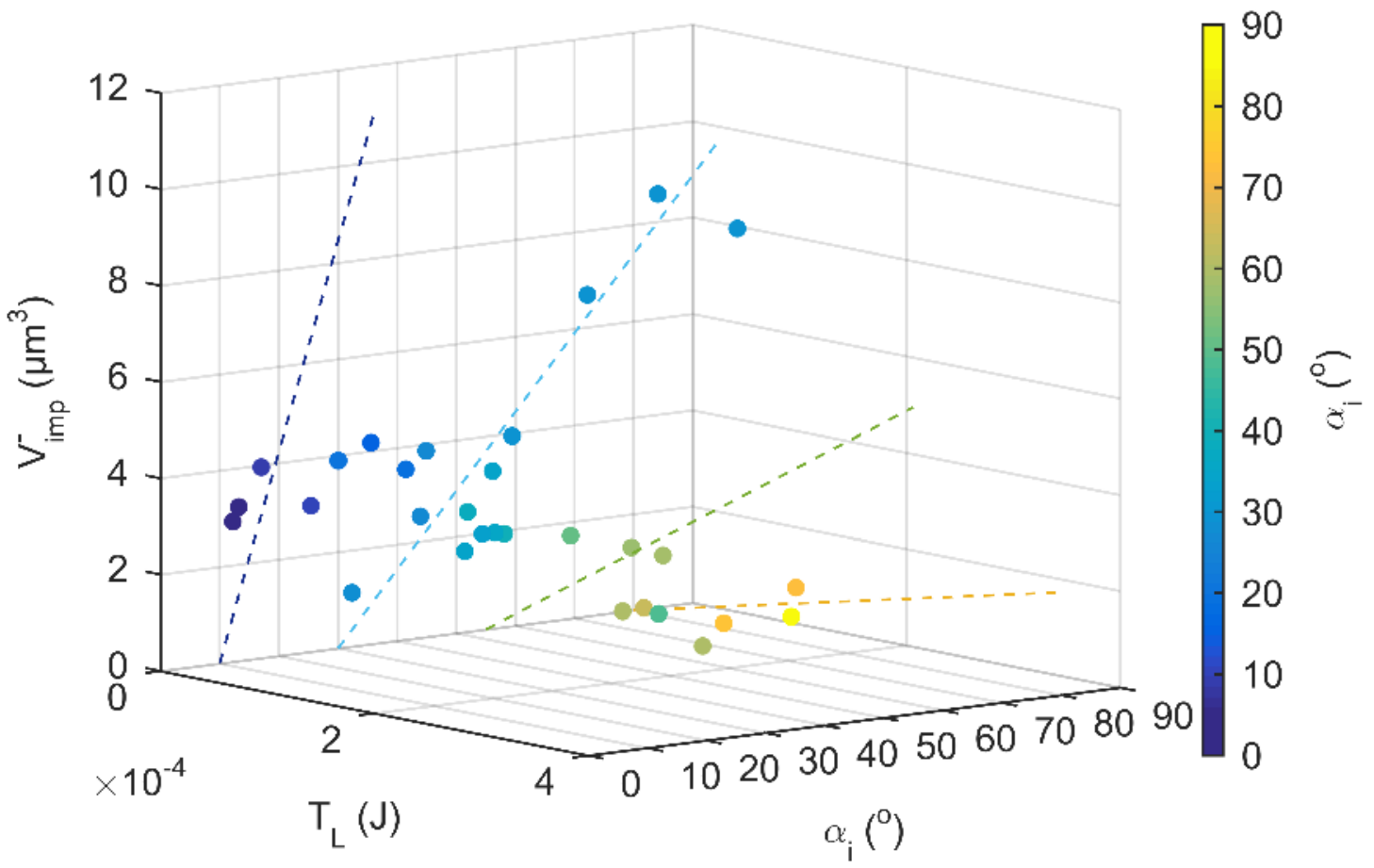

Fig. 13. Wear volume per impact versus impact energy loss and incidence angle; color: incidence angle; dotted lines: linear fits. 


\section{Conclusion}

Wear induced by repetitive impacts between a steam generator tube sample and an anti-vibration bar sample in water environment is studied with a specific impact wear test machine. A statistical analysis of the impacts characteristics shows that the restitution coefficient slightly increases with the incidence angle. A two-parts evolution of the impulse ratio with incidence angle is observed and well predicted by the proposed model. The energy loss during impacts is measured and is found to be well predicted by Brach's formulation. The sliding distance during impacts is measured and well predicted by the proposed model.

Wear volumes and worn surface topography obtained after $20 \mathrm{~h}$ tests of 1.4 million impacts is deeply analyzed. A direct proportionality is observed between the final value of impulse ratio during a wear test and the worn surface roughness. Wear is observed to be proportional to energy loss with a proportionality coefficient strongly influenced by the incidence angle. The energy loss alone is observed to be insufficient to predict wear: wear depends on both incidence angle and energy loss.

\section{References}

[1] Ko PL. Metallic wear - a review with special references to vibration-induced wear in power plant components. Tribol Int 1987;20:66-78. doi:10.1016/0301-679X(87)90092-2.

[2] Engel PA. Impact Wear of Materials. vol. 2. 2nd ed. Elsevier; 1978. doi:10.1115/1.3424343.

[3] Engel PA. Percussive impact wear. A study of repetitively impacting solid components in engineering. Tribol Int 1978;11:169-76. doi:10.1016/0301-679X(78)90002-6.

[4] Engel PA, Lyons TH, Sirico JL. Impact wear model for steel specimens. Wear 1973;23:185-201. doi:10.1016/0043-1648(73)90083-5.

[5] Levy G, Morri J. Impact fretting wear in CO2-based environments. Wear 1985;106:97-138. doi:10.1016/0043-1648(85)90106-1.

[6] Connors HJ. Flow-induced vibration and wear of steam generator tubes. Nucl Technol 1981;55:311-31. doi:10.13182/NT55-311.

[7] Frick TM. An empirical wear projection technology with steam generator tube applications and relations to work-rate and wear simulations/tests. Flow-Induced Vib Noise 1997;2:275-82.

[8] Hofmann PJ, Schettler T, Steininger DA. PWR steam generator tube fretting and fatigue wear phenomena and correlations. ASME Vib Noise 1992;1:211-36.

[9] Lewis R. A modelling technique for predicting compound impact wear. Wear 2007;262:1516-21. doi:10.1016/j.wear.2007.01.032.

[10] Gessesse YB. On the fretting wear of nuclear power plant heat exchanger tubes using a fracture mechanics approach: theory and verification. Concordia University (Canada), 1997. 
[11] Attia H. A generalized fretting wear theory. Tribol Int 2009;42:1380-8. doi:10.1016/j.triboint.2009.04.010.

[12] Shewmon P, Sundararajan G. The Erosion of Metals. Annu Rev Mater Sci 1983;13:301-18. doi:10.1146/annurev.ms.13.080183.001505.

[13] Finnie I. Erosion of surfaces by solid particles. Wear 1960;3:87-103. doi:10.1016/00431648(60)90055-7.

[14] Finnie I. Some observations on the erosion of ductile metals. Wear 1972;19:81-90. doi:10.1016/0043-1648(72)90444-9.

[15] Bitter JGA. A study of erosion phenomena. Wear 1963;6:169-90. doi:10.1016/00431648(63)90073-5.

[16] Hutchings IM. A model for the erosion of metals by spherical particles at normal incidence. Wear 1981;70:269-81. doi:10.1016/0043-1648(81)90347-1.

[17] Follansbee PS, Sinclair GB, Williams JC. Modelling of low velocity particulate erosion in ductile materials by spherical particles. Wear 1982;74:107-22. doi:10.1016/0043-1648(81)90197-6.

[18] Ratner SB, Styller EE. Characteristics of impact friction and wear of polymeric materials. Wear 1981;73:213-34. doi:10.1016/0043-1648(81)90292-1.

[19] Sundararajan G, Shewmon PG. A new model for the erosion of metals at normal incidence. Wear 1983;84:237-58. doi:10.1016/0043-1648(83)90266-1.

[20] Jahanmir S, Suh NP. Mechanics of subsurface void nucleation in delamination wear. Wear 1977;44:17-38. doi:10.1016/0043-1648(77)90082-5.

[21] Stronge WJ. Impact mechanics. Cambridge University Press; 2000.

[22] Brach RM. Impact dynamics with applications to solid particle erosion. Int J Impact Eng 1988;7:3753. doi:10.1016/0734-743X(88)90011-5.

[23] Brach RM. Classical planar impact theory and the tip impact of a slender rod. Int J Impact Eng 1993;13:21-33. doi:10.1016/0734-743X(93)90106-H.

[24] Guinot J. Etude Bibliographique des Travaux Expérimentaux menés sur I'usure par impacts glissements : influence des principaux paramètres. 1989.

[25] Zaghdoudi S. Analyse des phénomènes d'usure par choc et frottement. Université de Paris VI, 1992.

[26] Ko PL. Heat Exchanger Tube Fretting Wear: Review and Application to Design. J Tribol 1985;107:149. doi:10.1115/1.3261010.

[27] Cha JH, Wambsganss MW, Jendrzejczyk JA. Experimental study on impact/fretting wear in heat exchanger tubes. J Press Vessel Technol 1987;109:265-74. doi:10.1115/1.3264862.

[28] Blevins R. Vibration-Induced Wear of Heat exchanger tubes. J Eng Mater 1985;107. 
doi:10.1115/1.3225772.

[29] Sorokin GM, Polyanskaya TA. Machine for the investigations into the impact fatigue wear. Zavod Lab 1970;36:611-2.

[30] Rice SL. Reciprocating impact wear testing apparatus. Wear 1977;45:85-95. doi:10.1016/00431648(77)90104-1.

[31] Pick RJ, Brown K, Plumtree A. Techniques in the study of impact and sliding wear of Zircaloy-4. Wear 1979;52:381-92. doi:10.1016/0043-1648(79)90074-7.

[32] Kadmiri Y, Rigaud E, Perret-Liaudet J, Vary L. Experimental and numerical analysis of automotive gearbox rattle noise. J Sound Vib 2012;331:3144-57. doi:10.1016/j.jsv.2012.02.009.

[33] Souilliart T, Rigaud E, Le Bot A, Phalippou C. Energy-based wear law for oblique impacts in dry environment. Tribol Int 2016:To be published.

[34] Frick T, Sobek T, Reavis J. Overview on the development and implementation of methodologies to compute vibration and wear of steam generator tubes. Proc. ASME Symp. Flow-Induced Vib. Vol. 3, Vib. Heat Exch., vol. 3, 1984, p. 149-161.

[35] Axisa F, Desseaux A, Gibert R. Experimental study of tube/support impact forces in multi-span PWR steam generator tubes. ASME 1984.

[36] Hofmann P, Schettler T, Wieling N, Steininger DA. Influence of contact conditions on vibration induced wear of metals. Nucl Eng Des 1990;119:439-45. doi:10.1016/0029-5493(90)90183-X.

[37] Johnson KL. Contact mechanics 1984;19:109-10. doi:10.1016/0301-679X(86)90085-X.

[38] Souilliart T, Rigaud E, Le Bot A, Phalippou C. Wear generated by sliding impacts. Proc. Congrès Français Mécanique, Lyon: 2015, p. 1-9.

[39] Rigaud E, Le Bot A. Influence of incidence angle on wear induced by sliding impacts. Wear 2013;307:68-74. doi:10.1016/j.wear.2013.07.015.

[40] Souilliart T, Rigaud E, Phalippou C, Le Bot A, Phalippou C. Wear Induced By Stochastic Sliding Impacts. ASME 2015 Press. Vessel. Pip. Conf., Boston: ASME; 2015, p. 1-6. doi:10.1115/PVP201545811.

[41] Hutchings IM. Deformation of metal surfaces by the oblique impact of square plates. Int J Mech Sci 1977;19:45-52. doi:10.1016/0020-7403(77)90015-7.

[42] Neilson JH, Gilchrist A. Erosion by a stream of solid particles. Wear 1968;11:111-22. doi:10.1016/0043-1648(68)90591-7.

[43] Tilly GP. A two stage mechanism of ductile erosion. Wear 1973;23:87-96. doi:10.1016/00431648(73)90044-6.

[44] Sundararajan G. A comprehensive model for the solid particle erosion of ductile materials. Wear 1991;149:111-27. doi:10.1016/0043-1648(91)90368-5. 
[45] Wellinger K, Breckel H. Kenngrössen und Verschleiss beim Stoss metallischer Werkstoffe. Wear 1969;13:257-81. doi:10.1016/0043-1648(69)90249-X.

[46] Fricke R, Allen C. Repetitive impact wear of steels. Wear 1993;164:837-47. doi:10.1016/00431648(93)90085-Z. 